\title{
Jean-Paul Duviols, Pedro Ureña-Rib, Dictionnaire culturel des Caraibes
}

\section{Elena Pessini}

\section{Q OpenEdition}

10 Journals

\section{Édition électronique}

URL : http://journals.openedition.org/studifrancesi/7744

DOI : 10.4000/studifrancesi. 7744

ISSN : 2421-5856

Éditeur

Rosenberg \& Sellier

\section{Édition imprimée}

Date de publication : 1 décembre 2009

Pagination : $677-678$

ISSN : 0039-2944

\section{Référence électronique}

Elena Pessini, « Jean-Paul Duviols, Pedro Ureña-Rib, Dictionnaire culturel des Caraïbes », Studi Francesi [En ligne], 159 (LIII | III) | 2009, mis en ligne le 30 novembre 2015, consulté le 08 janvier 2021. URL : http://journals.openedition.org/studifrancesi/7744 ; DOI : https://doi.org/ERREUR PDO dans / localdata/www-bin/Core/Core/Db/Db.class.php L.34 : SQLSTATE[HY000] [2006] MySQL server has gone away

Ce document a été généré automatiquement le 8 janvier 2021.

\section{(c) ()) (9)}

Studi Francesi è distribuita con Licenza Creative Commons Attribuzione - Non commerciale - Non opere derivate 4.0 Internazionale. 


\title{
Jean-Paul Duviols, Pedro Ureña-Rib, Dictionnaire culturel des Caraibes
}

\author{
Elena Pessini
}

\section{RÉFÉRENCE}

JEAN-PAUL DUVIOLS, PEDRO UREÑA-RIB, Dictionnaire culturel des Caraibes, Paris, Ellipses, 2009,

pp. 397.

1 Le paratexte qui entoure ce dictionnaire tend à souligner l'ampleur du projet. Le soustitre avant tout (Histoire, Littérature, Arts plastiques, Musique, Traditions populaires, Biographies) qui égrène l'ensemble des domaines que cet ouvrage entend toucher, avec en toile de fond un dénominateur commun spatial. L'avant-propos, qui fixe les objectifs de façon générale: «ouvrir des perspectives et [...] réunir pour la première fois des cultures qui ont déjà une longue histoire commune», (p.5), se veut particulièrement précis quant à la géographie dont il va être question dans le texte. C'est très méticuleusement, qu'après les deux points qui suivent l'affirmation «Les états membres de la Caraïbe sont», les auteurs égrènent les noms de 25 états en rigoureux ordre alphabétique depuis Antigua-et-Barbuda jusqu'au Vénézuela, auxquels il faut ajouter les membres associés (dont la Guyane, la Martinique, la Guadeloupe et l'île de Porto Rico). C'est la phrase de René Depestre en ouverture du Dictionnaire: «Le bassin caraïbe - qu'une vision manichéenne présente comme des terres en flammes entourées d'une mer en ébullition - est en train de vivre une nouvelle étape de son aventure historique» (p. 7) qui trouve dans le moment historique une justification pour un ouvrage qui pourrait se prêter à des critiques, à cause justement des nombreux domaines qu'il aborde. Puisqu'il s'agit d'un dictionnaire, c'est l'ordre alphabétique qui guidera la lecture, une lecture qui a besoin de ce point de référence pour ne pas se perdre dans les méandres d'une terre constituée par un ensemble d'îles éclatées. Mais au fur et à mesure que le lecteur prend possession du texte, les zones de contact émergent, les dénominateurs communs se précisent, les renvois deviennent plus nombreux, la trame de la Caraibe se tisse. Le Dictionnaire offre une série d'entrées qui renvoient à la 
géographie de l'archipel. Pour chaque état, pour chaque île, sont fournies les informations essentielles que l'on pourrait trouver dans un guide ainsi que des données historiques qui témoignent souvent du passé tourmenté de la région. L'histoire est partout présente et l'entrée Abolition de l'esclavage en Amérique montre, avec son chapelet de dates qui ont sonné le glas d'une horrible pratique, que l'hypothèse d'une histoire commune aux Caraïbes n'est point fantaisiste. Le passé est évoqué et rappelé à travers tous ceux qui participèrent dans un camp et dans l'autre à la triste aventure de la découverte et de la colonisation. Bon nombre de peuples, de groupes ethniques dont la présence aux Caraïbes est attestée bien avant l'arrivée des européens trouvent leur place dans ce Dictionnaire; des peuples aujourd'hui disparus (Arawaks, Caquetios, Ciboneys, Guanajata bey...) et d'autres encore présents (Guajiros, Guaymis, Kunas,...) constituent les premières tesselles de la mosaïque humaine des Caraïbes. Ensuite arrivent des aventuriers, les boucaniers, les colonisateurs (Belain D'Esnambuc), les religieux (Las Casas, le Père Breton, le Père Du Tertre, le Père Labat), et, par le moyen que l'on sait, les noirs. On pourra s'étonner de remarquer une absence, celle du mot «traite», la pratique ayant contribué à constituer ce que les Caraïbes sont aujourd'hui devenues, mais si l'on cherche à Code Noir, Marron, Bois Caïman, Vertières, Schoelcher, Conspiración de la Escalera, le tableau de ce qui se passa là-bas au cours des siècles devient parlant.

2 Le passé est largement illustré mais l'on trouve une grande attention pour le présent de cette région du monde. La musique, les musiques, sont à l'honneur: la bachata et le merengue dominicains, la biguine louisianaise, le boléro, la conga, le danzón cubains, le reggae jamaïcain. Beaucoup d'informations sont données sur les groupes qui aujourd'hui composent et jouent dans la Caraïbe. La peinture, le cinéma, la gastronomie sont amplement illustrés. Les religions aussi, surtout celles qui sont nées sur ce territoire comme le vaudou haïtien et la santería brésilienne. Une grande place est faite à la littérature, avec ses écrivains bien sûr qui sont unis par le fait d'avoir écrit depuis et sur les Caraïbes, au-delà de leur couleur de peau, au-delà de leurs langues d'expression et que le Dictionnaire examine sur une grande plage temporelle. Se font ainsi écho les haïtiens Jacques-Stephen Alexis, Jacques Roumain, Gary Victor, avec les martiniquais Aimé Césaire, Édouard Glissant, les guadeloupéens Maryse Condé et Ernest Pépin, ces derniers dialoguant avec leurs collègues cubains, guyanais, guatémaltèques, jamaïcains, dominicains, etc. La longueur des entrées consacrées aux écrivains varie selon l'importance de ces derniers mais elles sont en général bien documentées et réussissent, malgré l'espace exigu que la nature même de l'ouvrage leur octroie, à fournir une série de données intéressantes sur chaque auteur et sur son œuvre. La littérature est présente aussi à travers les entrées consacrées aux mouvements littéraires (entre autres Indigénisme, Négritude, Créolité), aux revues ("L’Étudiant noir", “Caravelle", "Les Griots", "Horizons caraïbes", "Légitime Défense", "Revista de Avance"), aux groupes, aux mouvements qui se sont affirmés tout au long $\mathrm{du} \mathrm{xx}^{\mathrm{e}}$ siècle. Il faut souligner que les auteurs du Dictionnaire n'ont pas cédé à la tentation de ne citer que les écrivains les plus célèbres et universellement reconnus mais qu'ils ont su faire place à des voix mineures, à des talents qui viennent d'émerger et dont l'avenir nous dira s'ils méritaient ou non de faire partie de cette publication qui s'avère précieuse pour tous ceux qui s'intéressent à la culture des Caraïbes. 